\title{
Rates of stillbirth by gestational age and cause in Inuit and First Nations populations in Quebec
}

\author{
Nathalie Auger MD MSc, Alison L. Park MSc, Hamado Zoungrana MSc, Nancy Gros-Louis McHugh MSc, \\ Zhong-Cheng Luo MD PhD
}

Competing interests: None declared.

This article has been peer reviewed.

\section{Correspondence to:}

Nathalie Auger,

nathalie.auger@inspq.qc.ca

CMAJ 2013. DOI:10.1503

/cmaj.120945

\section{Abstract}

Background: Inuit and First Nations populations have higher rates of stillbirth than nonAboriginal populations in Canada do, but little is known about the timing and cause of stillbirth in Aboriginal populations. We compared gestational age- and cause-specific stillbirth rates in Inuit and First Nations populations with the rates in the non-Aboriginal population in Quebec.

Methods: Data included singleton stillbirths and live births at 24 or more gestational weeks among Quebec residents from 1981 to 2009. We calculated odds ratios (ORs), rate differences and $95 \%$ confidence intervals (Cls) for the retrospective cohort of Inuit and First Nations births relative to non-Aboriginal births using fetuses at risk (i.e., ongoing pregnancies) as denominators and adjusting for maternal characteristics. The main outcomes were stillbirth by gestational age (24-27, 28$36, \geq 37 \mathrm{wk}$ ) and cause of death.
Results: Rates of stillbirth per 1000 births were greater among Inuit (6.8) and First Nations (5.7) than among non-Aboriginal (3.6) residents. Relative to the non-Aboriginal population, the risk of stillbirth was greater at term ( $\geq 37 \mathrm{wk}$ ) than before term for both Inuit (OR 3.1, 95\% Cl 1.9 to 4.8 ) and First Nations (OR 2.6, 95\% Cl 2.1 to 3.3) populations. Causes most strongly associated with stillbirth were poor fetal growth, placental disorders and congenital anomalies among the Inuit, and hypertension and diabetes among the First Nations residents.

Interpretation: Stillbirth rates in Aboriginal populations were particularly high at term gestation. Poor fetal growth, placental disorders and congenital anomalies were important causes of stillbirth among the Inuit, and diabetic and hypertensive complications were important causes in the First Nations population. Prevention may require improvements in pregnancy and obstetric care.
A ttention has recently been drawn to the paucity of data on rates and causes of stillbirth, a pregnancy outcome that is largely ignored compared with later deaths. Aboriginal populations in Canada rank at the top of the list of disadvantaged groups with the highest rates of stillbirth in the Western world. ${ }^{1}$ First Nations and Inuit, 2 distinct Aboriginal populations in Canada, have stillbirth rates that are 2-3 times that among non-Aboriginal Canadians. ${ }^{1,2}$ Although these trends are alarming, little data exist to guide prevention efforts among Aboriginal Canadians. Not much is known about how stillbirth rates in Aboriginal populations vary by gestational age or cause of death, despite evidence that prevention requires knowledge on the timing and cause of stillbirth. ${ }^{3}$ Opportunities for preventing stillbirth are typically greater after 28 weeks of gestation, ${ }^{4}$ particularly at term, but the absence of gestational age- and cause-specific comparisons between Aboriginal and non-Aboriginal Canadians is a major impediment to reducing stillbirth rates. To gain a better understanding of the timing and causes of stillbirth in Inuit and First Nations populations, we estimated gestational age- and cause-specific fetal death rates in the Aboriginal and non-Aboriginal populations in the province of Quebec, where Inuit and First Nations people can be identified by parental information on birth registration forms.

\section{Methods}

\section{Data and variables}

Data included singleton stillbirths $(n=9983)$ and live births $(n=2397$ 971) in Quebec from 1981 to 2009 . We excluded 464 voluntary pregnancy terminations (International Classification of Disease [ICD]-9 code 779.6 and ICD-10 code P96.4). To maximize comparability with the prevailing literature, ${ }^{5}$ and because recording was 
potentially incomplete at very low gestational ages, we restricted statistical analyses to deliveries at 24 or more completed gestational weeks (8491 stillbirths, 2377284 live births). Gestational age was expressed in 3 categories (24-27, $28-36, \geq 37$ wk). Stillbirths after term at 42 or more weeks were rare (3 First Nations, 75 nonAboriginals) and were grouped with term births. Data on gestational age were missing for 346 stillbirths (3.5\%) and 18596 live births (0.8\%).

Causes of death were classified according to the ICD-9 and -10 (since 2000) codes (Appendix 1, available at www.cmaj.ca/lookup/suppl /doi:10.1503/cmaj.120945/-/DC1). The underlying cause of death recorded on registration forms was determined by physicians for most stillbirths (>97\%), although physicians were less likely to determine the cause of death for Inuit stillbirths (73.9\%), perhaps because midwife care is com- mon in some Inuit communities, especially in Hudson Bay. ${ }^{6}$ Using decision tables, trained nosologists at the Institut de la Statistique du Québec assigned an ICD code for the cause of death, which was subsequently validated by Statistics Canada. Other potentially useful classification systems for stillbirth were not used. ${ }^{1,3}$ Although placental pathology was not recorded on registration forms, autopsies were performed for most stillbirths (70.9\%). Autopsies were more common in the non-Aboriginal group $(71.5 \%)$ than in the Inuit and First Nations groups $(46.7 \%$ and $52.8 \%, p<0.001)$, for gestational ages of 28 or more weeks $(72.0 \%)$ versus 24-27 weeks $(65.4 \%, p<0.001)$, and for unexplained stillbirths $(79.1 \%)$ versus known causes $(68.1 \%, p<0.001)$. By law, stillbirth registration forms must be filed within 8 days after delivery in Quebec.

Table 1: Incidence of stillbirths at 24 or more gestational weeks among Inuit, First Nations and non-Aboriginal residents of Quebec, by maternal characteristics and period of data collection

\begin{tabular}{|c|c|c|c|c|c|c|c|c|c|}
\hline \multirow[b]{2}{*}{ Characteristic } & \multicolumn{3}{|c|}{ Inuit } & \multicolumn{3}{|c|}{ First Nations } & \multicolumn{3}{|c|}{ Non-Aboriginal } \\
\hline & Stillbirths & $\begin{array}{l}\text { Total } \\
\text { births }\end{array}$ & $\begin{array}{l}\text { Rate per } 1000 \\
\text { births }(95 \% \mathrm{Cl})\end{array}$ & Stillbirths & $\begin{array}{l}\text { Total } \\
\text { births }\end{array}$ & $\begin{array}{l}\text { Rate per } 1000 \\
\text { births }(95 \% \mathrm{Cl})\end{array}$ & Stillbirths & $\begin{array}{l}\text { Total } \\
\text { births }\end{array}$ & $\begin{array}{l}\text { Rate per } 1000 \\
\text { births }(95 \% \mathrm{Cl})\end{array}$ \\
\hline \multicolumn{10}{|l|}{ Maternal age, yr } \\
\hline$<20$ & 10 & 1596 & $6.8(2.5$ to 10.8$)$ & 33 & 6237 & 5.5 (3.7 to 7.3 ) & 381 & 83508 & 4.7 (4.2 to 5.2 ) \\
\hline $20-34$ & 29 & 4948 & 6.2 (4.0 to 8.4 ) & 108 & 20174 & 5.4 (4.5 to 6.5$)$ & 5832 & 1784201 & 3.4 (3.3 to 3.5 ) \\
\hline$\geq 35$ & $-\dagger$ & $-\dagger$ & 15.3 (3.1 to 27.4$)$ & 17 & 1881 & 9.5 (5.1 to 13.8$)$ & 896 & 191575 & 4.8 (4.5 to 5.1$)$ \\
\hline \multicolumn{10}{|l|}{ Education } \\
\hline $\begin{array}{l}\text { No secondary } \\
\text { school diploma }\end{array}$ & 13 & 3013 & 7.7 (4.8 to 10.5 ) & 73 & 13810 & 6.4 (5.0 to 7.8 ) & 1087 & 276671 & 5.2 (4.9 to 5.5 ) \\
\hline $\begin{array}{l}\text { Secondary school } \\
\text { diploma }\end{array}$ & $-\dagger$ & $-\dagger$ & 5.5 (1.3 to 9.6$)$ & 21 & 4313 & 5.9 (3.4 to 8.3$)$ & 865 & 272277 & 3.8 (3.6 to 4.1$)$ \\
\hline $\begin{array}{l}\text { Postsecondary } \\
\text { collegiate }\end{array}$ & $-\dagger$ & $-\dagger$ & 7.0 (0.0 to 13.9$)$ & 12 & 3549 & 4.7 (2.6 to 6.9 ) & 1652 & 546524 & 3.8 (3.6 to 3.9) \\
\hline $\begin{array}{l}\text { Some university } \\
\text { or more }\end{array}$ & $-\dagger$ & $-\dagger$ & 4.3 (0.0 to 11.7$)$ & $-\dagger$ & $-\dagger$ & $3.4(1.0-5.8)$ & 1933 & 875633 & 2.9 (2.8 to 3.0$)$ \\
\hline \multicolumn{10}{|l|}{ Marital status } \\
\hline Legally married & $-\dagger$ & $-\dagger$ & 7.4 (3.1 to 11.6$)$ & 52 & 10161 & 5.6 (4.1 to 7.1$)$ & 3527 & 1064940 & 3.6 (3.5 to 3.7 ) \\
\hline Not legally married* & 28 & 5327 & 6.7 (4.5 to 8.9 ) & 98 & 18131 & 5.8 (4.7 to 6.9$)$ & 3264 & 994150 & 3.6 (3.4 to 3.7 ) \\
\hline \multicolumn{10}{|l|}{ Parity } \\
\hline 0 & 27 & 2217 & 13.3 (8.6 to 18.0$)$ & 110 & 9362 & 12.0 (9.8 to 14.2$)$ & 6172 & 956092 & 6.7 (6.5 to 6.9 ) \\
\hline 1 & $-\dagger$ & $-\dagger$ & $2.7(0.1$ to 5.2$)$ & 12 & 7210 & 1.7 (0.7 to 2.6$)$ & 574 & 731739 & 0.8 (0.7 to 0.8$)$ \\
\hline$\geq 2$ & 14 & 3228 & $4.3(2.0$ to 6.5$)$ & 37 & 11729 & 3.1 (2.1 to 4.1$)$ & 389 & 371603 & $1.0(0.9$ to 1.1$)$ \\
\hline \multicolumn{10}{|l|}{ Study period } \\
\hline 1981-1989 & 11 & 1226 & 11.0 (5.3 to 17.0$)$ & 41 & 8050 & 5.2 (3.7 to 6.8$)$ & 3067 & 702071 & 4.6 (4.5 to 4.8$)$ \\
\hline 1990-1999 & 20 & 2758 & 7.1 (4.0 to 10.3 ) & 50 & 9725 & 5.3 (3.9 to 6.7 ) & 2329 & 729414 & 3.3 (3.1 to 3.4$)$ \\
\hline 2000-2009 & 14 & 2952 & 4.7 (2.3 to 7.2$)$ & 68 & 10526 & 6.5 (4.9 to 8.0$)$ & 1739 & 627949 & 2.8 (2.6 to 2.9$)$ \\
\hline All & 45 & 6936 & 6.8 (4.9 to 8.8$)$ & 159 & 28301 & 5.7 (4.8 to 6.6 ) & 7135 & 2059434 & 3.6 (3.5 to 3.7 ) \\
\hline
\end{tabular}


Aboriginal births were identified by language spoken at home, and maternal or paternal mother tongue, as well as municipality codes for Aboriginal communities. As the reference group for comparison, we selected residents of non-Aboriginal municipalities who identified themselves as French or English speakers. Covariates, selected for their potential to confound the relation between Aboriginal status and stillbirth, included maternal age ( $<20,20-34, \geq 35 \mathrm{yr}$ ), education (no secondary school diploma, secondary school diploma, postsecondary collegiate, some university or more), marital status (legally married or not), parity $(0,1, \geq 2$ previous deliveries) and period of data collection (1981-1990, 1991-2000, 2001-2009). For births with missing data on gestational age $(n=18942)$, and maternal age $(n=269)$, education $(n=146353)$ and marital status $(n=668)$, we used multiple imputation to impute the missing values based on the distribution of observed covariates for all births (including $<24 \mathrm{wk}$ ). ${ }^{7}$

\section{Outcome measures}

The primary outcomes were rates of stillbirth per 1000 births by gestational age and cause. We computed gestational age-specific rates using fetuses at risk (i.e., all live and stillborn infants in the gestational interval, plus ongoing pregnancies) in the denominator. ${ }^{8}$ These prospective rates provide estimates of the remaining risk of stillbirth during pregnancy ${ }^{9}$ and differ from conventional gestational age-specific rates wherein denominators contain only births that occurred in the gestational interval (not ongoing pregnancies). Conventional

Table 2: Incidence of stillbirths by Aboriginal status and gestational age

\begin{tabular}{|c|c|c|c|}
\hline $\begin{array}{l}\text { Gestational age; } \\
\text { Aboriginal status }\end{array}$ & Stillbirths & Total births & 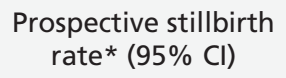 \\
\hline \multicolumn{4}{|l|}{ 24-27 weeks } \\
\hline Inuit & $-\dagger$ & $-t$ & $0.9(0.2$ to 1.5$)$ \\
\hline First Nations & 18 & 80 & $0.6(0.3$ to 0.9$)$ \\
\hline Non-Aboriginal & 1112 & 5047 & 0.5 (0.5 to 0.6$)$ \\
\hline \multicolumn{4}{|l|}{ 28-36 weeks } \\
\hline Inuit & 20 & 680 & 3.3 (1.9 to 4.6$)$ \\
\hline First Nations & 66 & 1806 & 2.5 (1.9 to 3.0$)$ \\
\hline Non-Aboriginal & 3224 & 117051 & 1.7 (1.6 to 1.7$)$ \\
\hline \multicolumn{4}{|l|}{$\geq 37$ weeks } \\
\hline Inuit & 19 & 6224 & 3.0 (1.7 to 4.4$)$ \\
\hline First Nations & 75 & 26415 & 2.8 (2.2 to 3.4$)$ \\
\hline Non-Aboriginal & 2799 & 1937336 & 1.4 (1.4 to 1.5$)$ \\
\hline \multicolumn{4}{|c|}{$\begin{array}{l}\text { Note: } \mathrm{Cl}=\text { confidence interval. } \\
\text { * Rate per } 1000 \text { fetuses at risk. To illustrate, the prospective stillbirth rate for the Inuit group } \\
\text { is calculated by dividing the } 20 \text { stillbirths at } 28-36 \text { weeks by the sum of the } 680 \text { total births at } \\
28-36 \text { weeks plus the } 6224 \text { total births at } \geq 37 \text { weeks, and then multiplying by } 1000 \text {. } \\
\text { †Not reported owing to low number }(<10) \text { of stillbirths. }\end{array}$} \\
\hline
\end{tabular}

stillbirth rates, which estimate the proportion of fetuses that died out of the total that were born, are deceptively high early in gestation because of the relatively low number of live preterm births. ${ }^{9}$

\section{Statistical analysis}

We estimated odds ratios (ORs), rate differences and $95 \%$ confidence intervals (CIs) for the association between Aboriginal status and stillbirth, adjusting for maternal age, education, marital status, parity and period of data collection. We calculated prospective (i.e., gestational age-specific) ORs and rate differences in regression models using fetuses at risk as the denominators of the underlying risk. To obtain regression denominators for fetuses at risk, we recoded all later stillbirths as live births in the model.$^{10}$ For example, prospective ORs at 28-36 weeks were obtained in models in which stillbirths at 28-36 weeks were compared with the combination of live births at 28 or more weeks and stillbirths at 37 or more weeks as the denominator. Prospective ORs help avoid potentially biased associations at preterm gestational ages from models that are stratified by gestational age. ${ }^{11}$ Stillbirths and preterm births share unmeasured risk factors, and regression of data stratified by gestational age can unintentionally make stillbirths appear more (or less) healthy than live preterm births, ${ }^{12,13}$ thus biasing results and rendering many previous studies difficult to interpret. ${ }^{14,15}$ Odds ratios from stratified models can also be attenuated or amplified by the underlying rates of preterm live births of Aboriginal subgroups.

We estimated cause-specific ORs for stillbirth and Aboriginal status relative to live births, adjusting for maternal age, education, marital status, parity and period of data collection.

In sensitivity analyses, we ran models excluding births at 42 or more weeks, excluding births with missing data on maternal age, education and marital status, and combining pregnancy terminations with congenital anomalies. To facilitate comparisons with European countries, we also performed analyses for births at 28 or more weeks of gestation. Finally, we ran models starting at 25 weeks of gestation, because Quebec's definition of stillbirth (fetal death with a birth weight $\geq 500 \mathrm{~g}$ ) may have missed the smallest $3 \%$ of stillbirths at 24 weeks. ${ }^{16}$

Data were anonymized, and formal ethics review was waived by the Ethics Review Board for Research on Human Subjects of the University of Montréal Hospital Centre.

\section{Results}

During the study period, 45 Inuit, 159 First Nations and 7135 non-Aboriginal stillbirths occurred at 24 or more weeks of gestation. Still- 
birth rates were higher in the Inuit (6.8 per 1000 total births) and First Nations (5.7 per 1000) groups than in the non-Aboriginal (3.6 per 1000) group (Table 1). Rates of stillbirth declined over time for all populations except First Nations. Prospective stillbirth rates increased with gestational age in all groups, but the increase was steeper in the Inuit group than in the First Nations and non-Aboriginal groups (Table 2). Differences in prospective stillbirth rates were large at term, especially between the Inuit and non-Aboriginal groups (3.0 v. 1.4 per 1000). However, differences before term were also elevated, especially at 28-36 weeks of gestation (Inuit 3.3 v. non-Aboriginal 1.7 per 1000). Prospective stillbirth rates in the First Nations group were not as large as rates in the Inuit group, although a divergence with advancing gestational age also occurred.

Overall, adjusted odds of stillbirth were 2.5 times higher in the Inuit than in the nonAboriginal population, and 1.9 times higher in the First Nations group (Table 3). Prospective ORs of stillbirth in both Aboriginal groups, especially the Inuit group, increased progressively with gestational age relative to the nonAboriginal population (Table 4). Adjusted odds were highest at term for both the Inuit (OR 3.05) and First Nations (OR 2.61) groups. Similarly, differences in the prospective stillbirth rate relative to the non-Aboriginal group increased with gestational age in both Aboriginal groups. At term, adjusted rate differences suggested that the Inuit had 1.24 and the First Nations group 1.04 more stillbirths (per 1000 births) compared with the non-Aboriginal population (Table 4).

Relative to the non-Aboriginal group, the Inuit group had greater adjusted odds of stillbirth caused by poor fetal growth or short gestation (OR 3.14); disorders of the placenta, amniotic sac, cord or cervix (OR 1.77); and congenital anomalies (OR 2.78) (Table 5). Although the same causes tended to be associated with stillbirth in the First Nations group, causes associ- ated with the highest risk were diabetes (OR 15.3) and hypertension (OR 2.25).

In the sensitivity analyses, exclusion of births at 24 or 42 or more gestational weeks and inclusion of pregnancy terminations had no effect on results; exclusion of births missing data on gestational age and maternal characteristics led to weaker and statistically nonsignificant associations before term in the Inuit group, but no change in the First Nations group (data not shown). Similarly, analyses restricted to births at 28 or more weeks did not change the pattern of results (Appendix 2, available at www.cmaj.ca /lookup/suppl/doi:10.1503/cmaj.120945/-/DC1).

\section{Interpretation}

In this study, we showed that stillbirth rates in Aboriginal populations of Quebec were high throughout pregnancy, especially among the Inuit women. Although it is encouraging that rates of stillbirth fell over time in the Inuit and non-Aboriginal populations, no improvement occurred in the First Nations group. Inequalities in stillbirth risk between Aboriginal and nonAboriginal populations were particularly wide in late gestation ( $\geq 28 \mathrm{wk}$ ), and peaked at 37 weeks or later. These findings are of concern because stillbirth in the third trimester is potentially preventable, especially at term. ${ }^{1,4}$ Prevention may require improvements in pregnancy and obstetric care, although additional opportunities for prevention may be sought through modification of behavioural risk factors. Causes most strongly associated with stillbirth among the Inuit (poor fetal growth, placental disorders and congenital anomalies) and First Nations people (diabetes and hypertension) in our study are potentially sensitive to reduction of tobacco use or obesity. ${ }^{1,5}$ Both smoking and obesity are prevalent in these communities. ${ }^{17}$

Our findings regarding stillbirth rates at term among Inuit and First Nations people contrast with the previously reported finding that Aboriginal people in Australia have higher stillbirth

Table 3: Risk of stillbirth at 24 or more weeks of gestation, by Aboriginal status

\begin{tabular}{|lccc|}
\hline Aboriginal status & Unadjusted OR $(95 \% \mathrm{Cl})$ & Adjusted* OR (95\% Cl) & $\begin{array}{c}\text { Adjusted rate } \\
\text { differencet }(95 \% \mathrm{Cl})\end{array}$ \\
\hline Inuit & $1.92(1.44$ to 2.55$)$ & $2.49(1.86$ to 3.32$)$ & $2.16(0.19$ to 4.13$)$ \\
\hline First Nations & $1.60(1.37$ to 1.87$)$ & $1.94(1.66$ to 2.28$)$ & 1.14 (0.35 to 1.93) \\
\hline Non-Aboriginal & 1.00 (ref) & 1.00 (ref) & 0.00 (ref) \\
\hline $\begin{array}{l}\text { Note: } \mathrm{Cl}=\text { confidence interval, OR = odds ratio, ref = reference group. } \\
\text { *Adjusted for maternal age, education, marital status, parity and period of data collection. } \\
\text { tDifference in the stillbirth rate (per } 1000 \text { births) between the Aboriginal and non-Aboriginal groups, adjusted for maternal } \\
\text { age, education, marital status and period of data collection (models including parity yielded unstable estimates). }\end{array}$ \\
\hline
\end{tabular}


rates before term than non-Aboriginal Australians have. ${ }^{18}$ In the United States, the risk of stillbirth among black people is greatest at 20-24 weeks and at term compared with white people. ${ }^{19}$ We were unable to determine how inequalities in stillbirth rates between Aboriginal and nonAboriginal groups in Quebec before 24 weeks compared with those in the US, because data were incomplete. Efforts are needed to record stillbirths at low gestational ages more completely in Quebec.

Table 4: Risk of stillbirth by Aboriginal status and gestational age

\begin{tabular}{|c|c|c|}
\hline $\begin{array}{l}\text { Gestational age; } \\
\text { Aboriginal status }\end{array}$ & Adjusted* OR $(95 \% \mathrm{Cl})$ & $\begin{array}{c}\text { Adjusted rate } \\
\text { differencet }(95 \% \mathrm{Cl})\end{array}$ \\
\hline \multicolumn{3}{|l|}{ 24-27 weeks } \\
\hline Inuit & $1.80(0.80$ to 4.05$)$ & $0.20(-0.39$ to 0.79$)$ \\
\hline First Nations & 1.29 (0.80 to 2.07$)$ & $-0.06(-0.29$ to 0.17$)$ \\
\hline Non-Aboriginal & 1.00 (ref) & 0.00 (ref) \\
\hline \multicolumn{3}{|l|}{ 28-36 weeks } \\
\hline Inuit & 2.37 (1.56 to 3.61$)$ & $0.94(-0.45$ to 2.33$)$ \\
\hline First Nations & 1.68 (1.32 to 2.14$)$ & $0.26(-0.34$ to 0.86$)$ \\
\hline Non-Aboriginal & 1.00 (ref) & 0.00 (ref) \\
\hline \multicolumn{3}{|l|}{$\geq 37$ weeks } \\
\hline Inuit & 3.05 (1.93 to 4.82 ) & $1.24(-0.15$ to 2.63$)$ \\
\hline First Nations & 2.61 (2.05 to 3.30$)$ & 1.04 (0.44 to 1.64$)$ \\
\hline Non-Aboriginal & 1.00 (ref) & 0.00 (ref) \\
\hline \multicolumn{3}{|c|}{$\begin{array}{l}\text { Note: } \mathrm{Cl}=\text { confidence interval, } \mathrm{OR}=\text { odds ratio, ref }=\text { reference group. } \\
\text { *Adjusted for maternal age, education, marital status and parity, and period of data } \\
\text { collection. } \\
\text { tDifference in the stillbirth rate (per } 1000 \text { births) between the Aboriginal and non- } \\
\text { Aboriginal groups, adjusted for maternal age, education, marital status and period of data } \\
\text { collection (models including parity yielded unstable estimates). }\end{array}$} \\
\hline
\end{tabular}

The high rates of stillbirth at term in the Inuit and First Nations groups nonetheless are cause for concern, especially the possibility that quality of antenatal care may underlie the disparities. The rate of perinatal infant death in Inuit regions in Quebec is lower with physician-led than with midwife-led care, although the difference is statistically nonsignificant. ${ }^{6}$ Optimizing antenatal care through early delivery in high-risk pregnancies is an option, but potential benefits are uncertain and should be weighed against the risk of infant death. Effects of preterm birth on morbidity also may not be negligible. ${ }^{20}$ Whereas the benefit of obstetric intervention before term is unclear, it is more difficult to argue against labour induction, or at least close obstetric follow-up, at term. Further, suboptimal quality of stillbirth data, owing to probable nondifferential misclassifications of the cause of death with the $\mathrm{ICD}^{21}$ and incomplete use of autopsy, especially among Aboriginal people, is a challenge.

Our cause-specific stillbirth rates likely represent conservative estimates, although they point to different routes for prevention. Poor fetal growth and placental disorders may be sensitive to tobacco use, a known risk factor for stillbirth $^{1,22}$ that is prevalent in Inuit and First Nations populations..$^{17,23,24}$ Other risk factors such as substance use $\mathrm{e}^{24,25}$ and folate deficiency ${ }^{26}$ could be targeted for congenital anomalies. ${ }^{22}$ Efforts to prevent diabetes, a major risk factor for stillbirth, ${ }^{27}$ may be warranted because the prevalence of diabetes in First Nations is 3 times that of the rest of Canada ( $15.5 \%$ v. $4.7 \%)$, and rates are steadily increasing. ${ }^{17}$ Obesity is also prevalent in First

Table 5: Risk of stillbirth at 24 or more gestational weeks, by Aboriginal status and cause

\begin{tabular}{|c|c|c|c|c|c|c|}
\hline Cause of death & $\begin{array}{l}\text { Stillbirth rate per } \\
1000 \text { births }(95 \% \mathrm{Cl})\end{array}$ & $\begin{array}{l}\text { Adjusted OR } \\
(95 \% \mathrm{Cl})^{*}\end{array}$ & $\begin{array}{l}\text { Stillbirth rate per } \\
1000 \text { births }(95 \% \mathrm{CI})\end{array}$ & $\begin{array}{l}\text { Adjusted OR } \\
(95 \% \mathrm{Cl})^{*}\end{array}$ & $\begin{array}{c}\text { Non-Aboriginal } \\
\text { Stillbirth rate per } \\
1000 \text { births }(95 \% \mathrm{Cl})\end{array}$ & $\begin{array}{l}\text { Total } \\
\text { stillbirths }\end{array}$ \\
\hline $\begin{array}{l}\text { Disorder of the } \\
\text { placenta, amniotic } \\
\text { sac, cord, cervix }\end{array}$ & 1.9 (1.0 to 3.1$)$ & 1.77 (1.02 to 3.06$)$ & 2.1 (1.6 to 2.7 ) & 1.83 (1.41 to 2.39$)$ & 1.3 (1.3 to 1.4$)$ & 2744 \\
\hline $\begin{array}{l}\text { Congenital } \\
\text { anomaly }\end{array}$ & 0.9 (0.3 to 1.9$)$ & $2.78(1.23$ to 6.28$)$ & 0.7 (0.4 to 1.1$)$ & 2.07 (1.31 to 3.27$)$ & $0.4(0.4$ to 0.4$)$ & 832 \\
\hline Hypertension & $-\dagger$ & $-\dagger$ & 0.2 (0.0 to 0.4$)$ & 2.25 (0.98 to 5.19$)$ & 0.1 (0.1 to 0.1$)$ & 234 \\
\hline Diabetes & $-\dagger$ & $-\dagger$ & 0.5 (0.3 to 0.8$)$ & 15.30 (8.39 to 27.9$)$ & 0.0 (0.0 to 0.1$)$ & 107 \\
\hline Other & 1.1 (0.5 to 2.3 ) & $3.23(1.60$ to 6.53$)$ & 0.6 (0.3 to 0.9$)$ & 1.47 (0.89 to 2.43$)$ & 0.5 (0.5 to 0.6$)$ & 1061 \\
\hline
\end{tabular}


Nations communities. ${ }^{17}$ The extent to which stillbirths due to hypertension among First Nations people can be prevented through modification of lifestyle is unclear. There may also be genetic contributions to the differences in risk. ${ }^{28}$ Many stillbirths were unexplained and may have been related to smoking or other preventable causes. ${ }^{29}$

\section{Limitations}

We were limited by lack of information on risk factors such as income, smoking, maternal body mass index and substance use, although adjustment for such potential mediators may inadvertently attenuate the true differences in risk. We may have misclassified a proportion of Aboriginal births as non-Aboriginal, but this is unlikely to have affected non-Aboriginal stillbirth rates because of the much larger non-Aboriginal population. Ultrasonography is widely used to date gestation in Quebec, but the degree to which dating is based on ultrasonography in Aboriginal areas is unclear, especially in earlier study periods. Underregistration of stillbirths in Aboriginal groups is possible ${ }^{30}$ and may have attenuated the disparities between the Aboriginal and nonAboriginal groups, especially at low gestational ages. Health care delivery for Inuit and some First Nations groups in Quebec relies on provincial funding, and Health Canada funds health care for First Nations not covered under provincial agreement. ${ }^{31}$ Generalizability of the findings to other Canadian settings or alternate health care systems remains to be determined.

\section{Conclusion}

We found that stillbirth rates were higher among Inuit and First Nations than among non-Aboriginal residents of Quebec. The gap widened at later gestational ages and was largest at term, a period when most stillbirths are potentially preventable. Although cause-specific data on stillbirths were not optimal, poor fetal growth, placental disorders and congenital anomalies, which may be linked to smoking, predominated in the Inuit group, and diabetic and hypertensive complications, which may be linked to obesity, predominated in the First Nations group. This suggests opportunities for prevention through smoking and weight-reduction programs targeting women of reproductive age, and promotion of health education. Research on the roles of health care delivery and behaviour modification for prevention of term stillbirth is needed, and better collection of stillbirth data over the range of gestational age and by cause of death is required to more accurately measure inequalities in stillbirth between Aboriginal and non-Aboriginal people.

\section{References}

1. Flenady V, Middleton P, Smith GC, et al. Stillbirths: the way forward in high-income countries. Lancet 2011;377:1703-17.

2. Aljohani N, Rempel BM, Ludwig S, et al. Impact of diabetes on maternal-fetal outcomes in Manitoba: relationship with ethnic and environmental factors. Clin Invest Med 2008;31:E338-45.

3. The Stillbirth Collaborative Research Network Writing Group. Causes of death among stillbirths. JAMA 2011;306:2459-68.

4. Smith GCS, Fretts RC. Stillbirth. Lancet 2007;370:1715-25.

5. Flenady V, Koopmans L, Middleton P, et al. Major risk factors for stillbirth in high-income countries: a systematic review and meta-analysis. Lancet 2011;377:1331-40.

6. Simonet F, Wilkins R, Labranche E, et al. Primary birthing attendants and birth outcomes in remote Inuit communities - a natural "experiment" in Nunavik, Canada. J Epidemiol Community Health 2009;63:546-51.

7. Sterne JA, White IR, Carlin JB, et al. Multiple imputation for missing data in epidemiological and clinical research: potential and pitfalls. BMJ 2009;338:b2393.

8. Yudkin PL, Wood L, Redman CWG. Risk of unexplained stillbirth at different gestational ages. Lancet 1987;1:1192-4.

9. Wilcox AJ, Weinberg CR. Invited commentary: analysis of gestational age-specific mortality — on what biological foundations? Am J Epidemiol 2004;160:213-4.

10. Auger N, Delézire P, Harper S, et al. Maternal education and stillbirth: estimating gestational-age-specific and cause-specific associations. Epidemiology 2012;23:247-54.

11. Wilcox AJ, Weinberg CR, Basso O. On the pitfalls of adjusting for gestational age at birth. Am J Epidemiol 2011;174:1062-8.

12. VanderWeele TJ, Mumford SL, Schisterman EF. Conditioning on intermediates in perinatal epidemiology. Epidemiology 2012; 23:1-9.

13. Paneth N. Stillbirth: still important and still a puzzle. Epidemiology 2012;23:255-6.

14. Balchin I, Whittaker JC, Patel RR, et al. Racial variation in the association between gestational age and perinatal mortality: prospective study. BMJ 2007;334:833.

15. Coory M. An investigation into the disparity between Australian Aboriginal and Caucasian perinatal mortality rates. Ann Epidemiol 1995;5:393-9.

16. Mikolajczyk RT, Zhang J, Betran AP, et al. A global reference for fetal-weight and birthweight percentiles. Lancet 2011;377: 1855-61.

17. Health Council of Canada. The health status of Canada's First Nations, Métis and Inuit peoples. Toronto (ON): The Council; 2005. p. 1-78. Available: www.healthcouncilcanada.ca/tree 2.03-BkgrdHealthyCdnsENG.pdf (accessed 2012 June 5).

18. Coory M. Gestational-age-specific stillbirth risk among Australian Aborigines. Int J Epidemiol 1998;27:83-6.

19. Willinger M, Ko CW, Reddy UM. Racial disparities in stillbirth risk across gestation in the United States. Am J Obstet Gynecol 2009;201:469.e1-e8.

20. Saigal S, Doyle LW. An overview of mortality and sequelae of preterm birth from infancy to adulthood. Lancet 2008;371:261-9.

21. Cockerill R, Whitworth MK, Heazell AEP. Do medical certificates of stillbirth provide accurate and useful information regarding the cause of death? Paediatr Perinat Epidemiol 2012;26:117-23.

22. Hendrix N, Berghella V. Non-placental causes of intrauterine growth restriction. Semin Perinatol 2008;32:161-5.

23. Plaziac C, Hamel D, Rochette L. Nunavik Inuit Health Survey 2004: Qanuippitaa? How are we? Tobacco use. Québec (QC): Institut national de santé publique du Québec and Nunavik Regional Board of Health and Social Services; 2007, p. 1-9. Available: www.inspq.qc.ca/pdf/publications/667_esi_tobacco pdf (accessed 2012 June 5).

24. Muckle G, Laflamme D, Gagnon J, et al. Alcohol, smoking, and drug use among Inuit women of childbearing age during pregnancy and the risk to children. Alcohol Clin Exp Res 2011;35: 1081-91.

25. Healey GK, Meadows LM. Inuit women's health in Nunavut, Canada: a review of the literature. Int J Circumpolar Health 2007;66:199-214.

26. De Wals P, Tairou F, Van Allen MI, et al. Reduction in neuraltube defects after folic acid fortification in Canada. $N$ Engl J Med 2007;357:135-42.

27. The Stillbirth Collaborative Research Network Writing Group. Association between stillbirth and risk factors known at pregnancy confirmation. JAMA 2011;306:2469-79.

28. Reich D, Patterson N, Campbell D, et al. Reconstructing Native American population history. Nature 2012;488:370-4.

29. Sutan R, Campbell D, Prescott GJ, et al. The risk factors for unexplained antepartum stillbirths in Scotland, 1994 to 2003. J Perinatol 2010;30:311-8. 
30. Smylie J, Fell D, Ohlsson A. A review of Aboriginal infant mortality rates in Canada: striking and persistent Aboriginal/nonAboriginal inequities. Can J Public Health 2010;101:143-8.

31. Ministère de la Santé et des Services sociaux. Delivery and funding of health services and social services for aboriginal people (First Nations and Inuit) - frame of reference. Government of Quebec; 2007. p. 1-30. Available: http://publications .msss.gouv.qc.ca/acrobat/f/documentation/2007/07-725-02A.pdf (accessed 2012 Dec. 05)

Affiliations: From the Institut national de santé publique du Québec (Auger, Park); University of Montréal Hospital Research Centre (Auger, Park); the Department of Social and Preventive Medicine (Auger), University of Montréal, Montréal, Que.; the Nunavik Regional Board of Health and Social Services (Zoungrana), Kuujjuaq, Que.; the First Nations of Quebec and Labrador Health and Social Services Commission (McHugh), Wendake, Que.; and the Department of Obstetrics and Gynecology (Luo), University of Montréal, Sainte-Justine Hospital, Montréal, Que.
Contributors: Nathalie Auger conceived and designed the study. Alison Park undertook the statistical analyses, and Zhong-Cheng Luo helped define the methodology with Hamado Zoungrana and Nancy Gros-Louis McHugh. Nathalie Auger and Alison Park drafted the manuscript, which Hamado Zoungrana, Nancy Gros-Louis and ZhongCheng Luo revised for important intellectual content. All of the authors approved the final manuscript submitted for publication.

Funding: This study was funded by the Establishment of young researchers - Junior 1 award from the Fonds de recherche du Québec — Santé (FRQ-S). The study sponsors had no role in the design of the study; the collection, analysis or interpretation of data; the writing of the report; or the decision to submit the article for publication. The authors acknowledge career awards from the FRQ-S (Auger) and the Canadian Institutes of Health Research (Luo). 